\title{
Communicating COVID-19 Pandemic on Facebook: Illustrations from Users' Screenshots from Nigeria and Bangladesh
}

\author{
Habib Mohammad Ali ${ }^{a}$, Herbert Batta ${ }^{\mathrm{b}}$, Henry C. Ogaraku ${ }^{\mathrm{c}}$ \\ ${ }^{a}$ University of Liberal Arts Bangladesh \\ bUniversity of Uyo, Nigeria \\ cLagos Aviation \& Maritime Business Academy, Uyo Campus, Nigeria
}

\begin{abstract}
The outbreak of COVID-19 has dented the global public health profile. On the one side, the ubiquity of social media has led to damaging misinformation, fake news, stigmatization, and conspiracy theories. Fortunately, on the other side, the advantageous characteristics of social media and the informational support mechanisms with which they produce social safety valves; are a solid basis to curbing the pandemic. This paper examines the use of social media as a valuable platform to publicly communicate the COVID19, especially its scientific discourses. This paper focuses on Facebook as a platform amenable to the strategic digital communication of COVID-19. It takes illustrations from screenshots of Facebook users in Nigeria and Bangladesh. Some of the identified strategies include supporting for preventive measures, focusing on solutions, countering fake information, standing against racism and stigmatization, relying on scientific facts, confronting conspiracy theories, dealing with pseudoscience and denials, explaining statistics meaningfully, avoiding the temptation to trivialize and sensationalize, and using local languages.
\end{abstract}

Keywords: social media strategies, science communication, social support, COVID-19 pandemic.

\section{Article History}

Received: 23 December 2020

Revised: 9 February 2021

Accepted: 26 February 2021

\section{Introduction}

The COVID-19 has led to the stagnation, recession, or depression of most of the world's economies. Given how the world is reeling under the effects of pandemics and emerging diseases, it is apposite to secure an appreciable understanding of what the COVID-19 pandemic entails (Finset et al., 2020; Liao et al., 2020; Moreno et al., 2020).

This paper has several backgrounds and presumptions. First, the current global disease is a health, economic, and communication problem. People must necessarily contend with misinformation, conspiracy theories, trivialization, sensationalism, finger-pointing, and 
making scapegoats (Bunker, 2020; Chan et al., 2020). If not appropriately addressed, these problems can burden the circumstances and diminish the efforts of the government, health authorities, and significant stakeholders. At this point, communication is crucial in resolving or exacerbating this problem.

Second, due to its pervasiveness, social media can also help to solve some of these problems when used appropriately. In this sense, it is crucial to develop social media guidelines to curtail the harmful effects of the pandemic. Therefore, it is essential to examine the social media platform available for communicating the pandemic (Kumar et al., 2021) and explore the attributes of social media that make them veritable tools of health communication (Dadaczynski et al., 2021). As the COVID-19 is globally widespread, there is a need to harness all kinds of communication channels to inform, educate, mobilize and sensitize large swaths of the world population to take prompt action against the malady (Finset et al., 2020; Liao et al., 2020; Moreno et al., 2020).

Third, there are even stronger reasons to communicate health/medical science and technology matters for developing countries because they have noticeable effects on the economy, education, health systems, and infrastructure (Chetty, 2012). Communication also contributes heavily to health literacy, impacting health promotion, disease prevention, food security, water management, environmental conservation, and rural development (Davies \& Priestley, 2017).

In Bangladesh, a lower-middle-income country with a vast population (165 million), measures directed at addressing COVID-19 face several challenges. Country lockdown, travel bans, remote office work, and social distancing are challenging to implement in some areas because of limited resources (Anwar et al., 2020). Besides, COVID-19 poses a significant mental health threat among children in Bangladesh (Yeasmin et al., 2020). The children suffered major to mild depressive disorders. Likewise, in the general Bangladeshi population, Islam et al. (2020: 30) found out that a sizable proportion of the study population "reported panic and generalized anxiety in the setting of COVID-19." It suggests the need for evidence-based intervention schemes and supportive strategies to curb the problem.

While in Nigeria, despite the existing digital gap, the penetration of the internet has increased exponentially. In 2020, about 98.39 million were Internet users, and 29.3 million were social network users. Of that number, 20.5 million were active on Facebook. The Nigerian sends or receives messages daily, $75 \%$ on Instagram, $85 \%$ on WhatsApp, $53 \%$ on YouTube, and 54\% on Facebook Messenger (Udodiong, 2020).

Focusing on Bangladesh and Nigeria as the cases, the problem is how social media may be optimized to communicate the COVID-19 pandemic to curb its spread and impact. This article aims to examine the character and attributes of the social media that make them 
suitable for communication of COVID-19 pandemic; exploring the social media to communicate the pandemic effectively.

\section{Method}

The method used is exploratory and textual analysis (Daymon \& Immy, 2011). The materials are mainly Facebook content about the COVID-19 pandemic in Nigeria and Bangladesh. This research has captured thirteen COVID-19 related messages in screenshots from Facebook walls of users from Nigeria and Bangladesh for examination. The observation period was from March to July 2020, during the first wave of the COVID-19 global lockdown. The text analyses aim as narrative and illustrative examples rather than empirical-based data sets.

This article purposively chose Nigeria and Bangladesh as they share several similarities. Apart from having a similar colonial heritage, both countries have a large population. They are both low-middle income countries and are geographically located in the tropics with numerous Muslim citizens. These two countries will be analyzed for complementarity.

\section{The use of social media in health/science communication}

Spreading factual information about COVID-19 requires the use of effective communication channels by credible sources to specific and targeted segments of the population for behavior modification or change (Hauer \& Sood, 2020). Social media have become veritable means of strategic communication in the digital age, used to promote knowledge, agendas, issues, and group-based objectives. Since the break out of the COVID-19 pandemic, social media, especially Facebook, have been deployed to communicate about the disease (Dadaczynski et al., 2021; Kumar et al., 2021).

The social media or digital networking platforms genuinely provide the enabling or supportive environment for users to exchange assistance through social relationships enacted and sustained in the cybersphere (Fergie et al., 2016; Holmes, 2020). Barnes (1954) describes patterns of social relationships not accommodated by family and workplace structures. Cassel (1976) investigates the relations between social relationships and health, pointing out that social support shielded people from the vulnerabilities mounted by health stressors. The structures, processes, and functions that occur in social relationships and social networks provide the grounds that help people wade through illness because of the social support they engender.

Concerning pandemics, the core assumptions of the social support concept can be applied as they pertain to social media, including emotional, instrumental, appraisal, and 
informational support. Social media allows people to form social relationships based on social networks, which generates digital social togetherness and offers opportunities for social support. These allow digital health awareness about the pandemic, making it possible for people in the network to learn about the nature, manifestations, and management of these disorders. They also help people adopt proper behaviors to prevent and treat the disease, including handwashing/sanitization, respiratory hygiene, physical distancing, face masks, personal protective wear, self-isolation, etc.

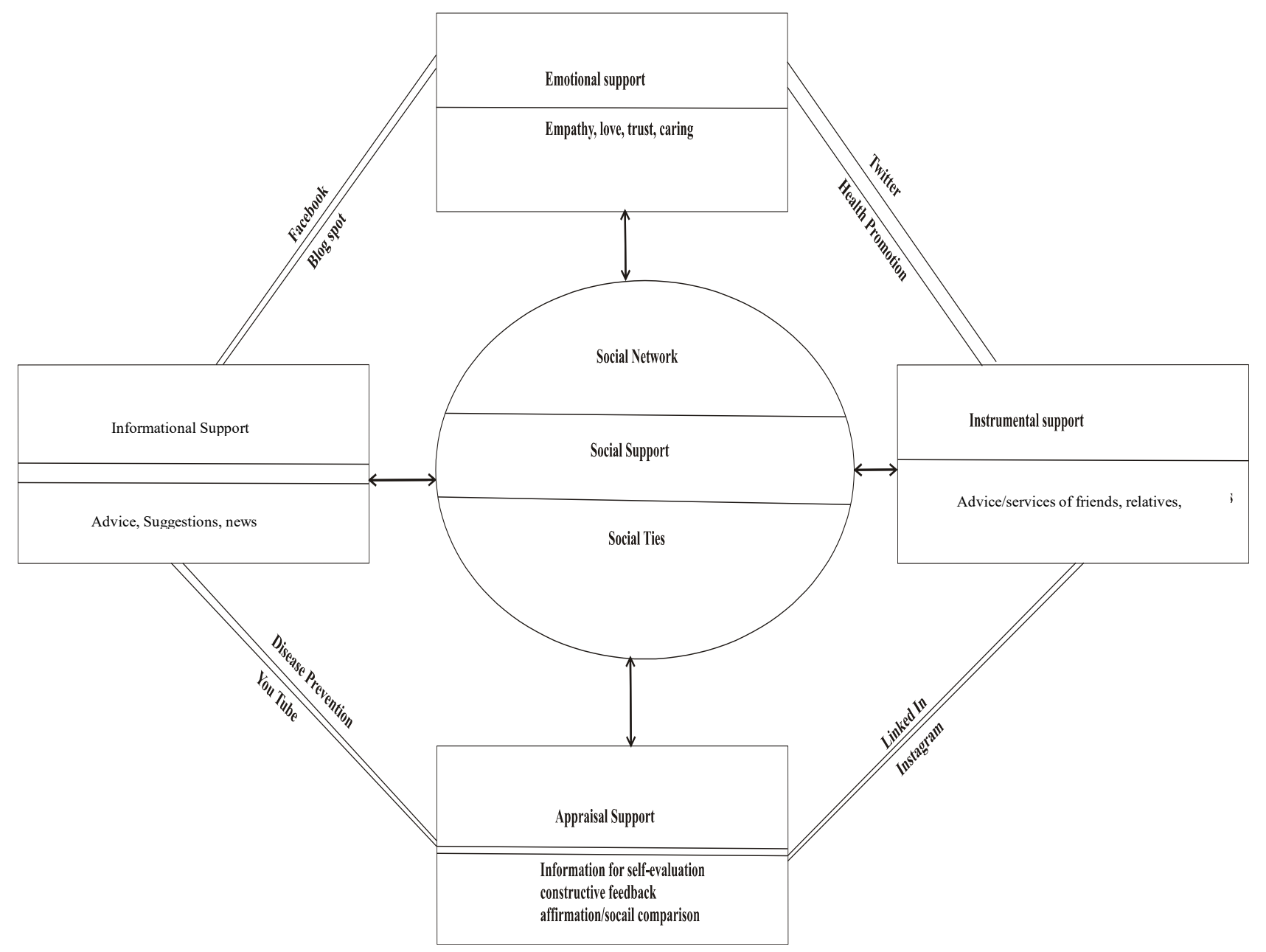

Figure 1. Social media and social support. Barnes (1954) first described the concept, expanded by Cassel (1976), and adapted here to conceptualize how social media engender the mechanisms necessary in response to a pandemic.

The prime place of social media in communicating health and science generally has now been established. The utility of social media for health and science is varied. Huber et al., (2019: 768) point out that they "expand and diversity information networks, promote engagement with news posted by trusted social contents [...] and provide direct access to science news posted by scientists and universities." Indeed, social media platforms enlarge 
how scientists, communicators, and the lay public interact with one another in science and health.

In developing countries where scientific advancement is at its lowest condition, expanding employment of social media "is an opportunity for dissemination of truthful information and engagement of the community; groups from trusted universities have the capacity of engaging new readers" (Sandalova et al., 2019: 9). Also, "large social media such as Facebook, Twitter, Instagram, and LinkedIn; allow patients to organize themselves and raise both awareness and funds for topics for which they share a common interest" (Sandalova et al., 2019: 2). These topics may necessarily include pandemics.

Indeed, there has been a blurring of the boundaries separating scientists, communicators, and the public because of the engagement in new forms of media such as social media, which have transformed science communication (Liang et al., 2014). For a large social media such as Facebook, researchers warn that ignoring the platform is at the peril of such people because it is "an effective form of online science communication" (Liang et al., 2014: 2). In this sense, the network affords users seven particular uses, i.e., social connection, shared identities, content, social investigation, social network surfing, and status updating. McClain (2017: 4) reveals that "40\% of all science-related posts on Facebook by participants were on controversial topics (e.g., climate change, vaccines, evolution, and genetically modified organisms)." During the pandemics, government agencies, science institutions, health organizations, specialists, and citizens use such opportunities to communicate.

For scientists, health, and medical researchers, social media help them in different ways. Wilkinson \& Weitkamp (2013) state that through social media, they create links with other scientists and people working in the industry, reach policymakers, get the public to learn about their research, increase the impact of their research in academic circles, obtain funding, attract important institutional endorsement, and internationalize research audience reach. Other benefits include improving the likelihood of contacts by lobbyists, the opportunity for research criticism by peers, the public, and policymakers, and projecting one's profile as a researcher. In other words, social media are a realistic platform for science communication. Osterrieder (2013: 6) argues, "understanding social media, and having the knowledge and confidence to use it appropriately and effectively [...] will become essential skills to be included in a scientist's skills tool kit." Van Eperen \& Marincola (2011) affirm that social media, particularly Twitter, Facebook, and Sciatable, are pillars of science communication.

However, using social media in health/science communication is not without a problem. Social media are multi-optional in technology; they allow open, digital science communication, leading to structural changes within science. According to Leopoldina et al. 
(2017), these aspects over the gatekeeper threshold in science and science journalism besides dissolving the distinction between specialists and the general public. It means that digitization (digital scientific public sphere) offers science communication "new and interesting opportunities for knowledge dissemination and dialogue between science and society [...], at the same time, they represent a challenge, possibly even a threat, to reflexive, moderated deliberation" (Leopoldina et al., 2017: 41). These challenges border on freedom, equality, integration, and quality of information/discussion, diversity, and transparency. Thus, it is sensible to avoid false incentives in science communication, evaluate costs and benefits of institutional science communication formats, separate fact-based science communication and science marketing, develop code of conduct for the web and social media, promote technological impact assessment of digital media, and strengthen public communication and demarcate role.

\section{Social media strategies for communicating COVID-19 pandemic}

Among social groups, it is apparent that social network platforms pervade the digital sphere and afford users of the platforms to offer social support to themselves and fellow users. Whether users are government agencies, science institutions, health authorities, science experts and individuals, social media channels should frequently, appropriately and ethically be used to provide emotional, informational, instrumental, and appraisal support.

In communicating the COVID-19 pandemic across social media channels, it is essential to adhere to the principles of simplicity, using unexpectedness, i.e., elements of surprise to draw and sustain audience attention, correctness and accuracy of the information, and use of credible/reliable sources (Zielińska, 2017). This paper recommends several communication strategies for communicating the pandemic in social media, i.e., supporting preventive measures, focusing on the solutions, countering fake information, standing against racism, finger-pointing and stigmatization, relying on scientific or evidencebased facts to allay fears, confronting conspiracy theories, dealing with pseudoscience, denials, and contrariness, explaining numbers and statistics meaningfully, avoiding the temptation to trivialize and sensationalize, and using local languages.

\section{a. Support for preventive measures}

Social media should focus on measures considered efficacious in preventing the pandemic. These measures are the use of faces, gloves, and personal protective equipment; maintenance of respiratory hygiene; hand washing and sanitizing; isolation; quarantine; vaccination; and physical distancing (Figure 2, 3 \& 4). 


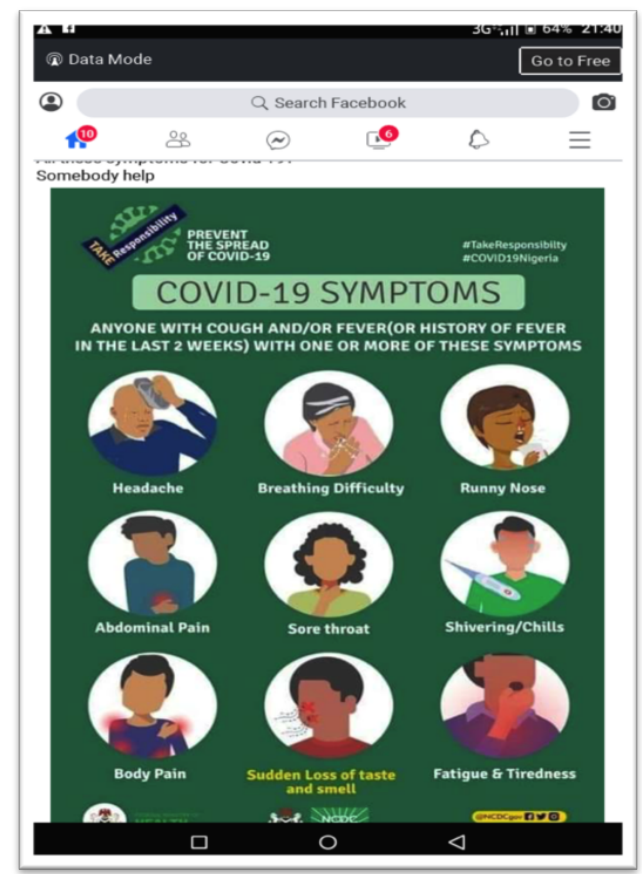

Figure 2. Example 1 of preventive measures.

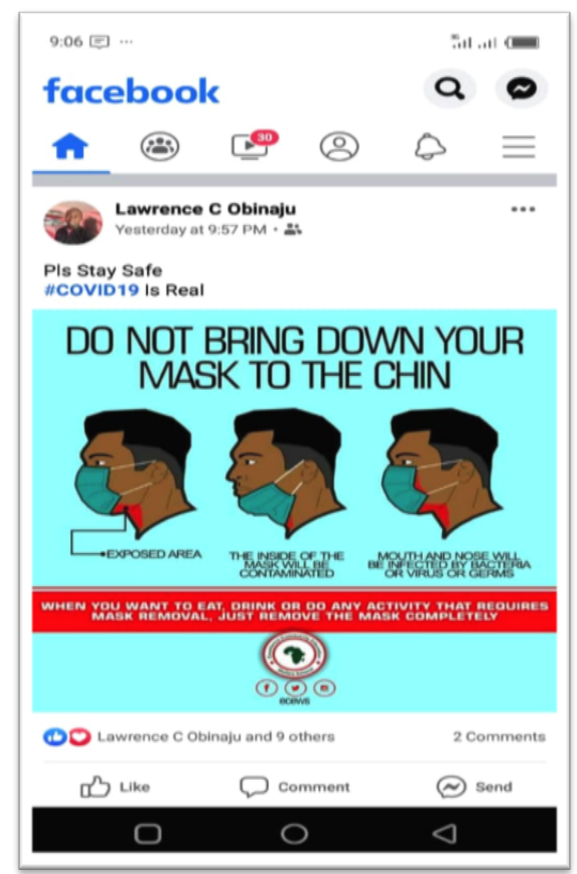

Figure 3. Example 2 of preventive measures.

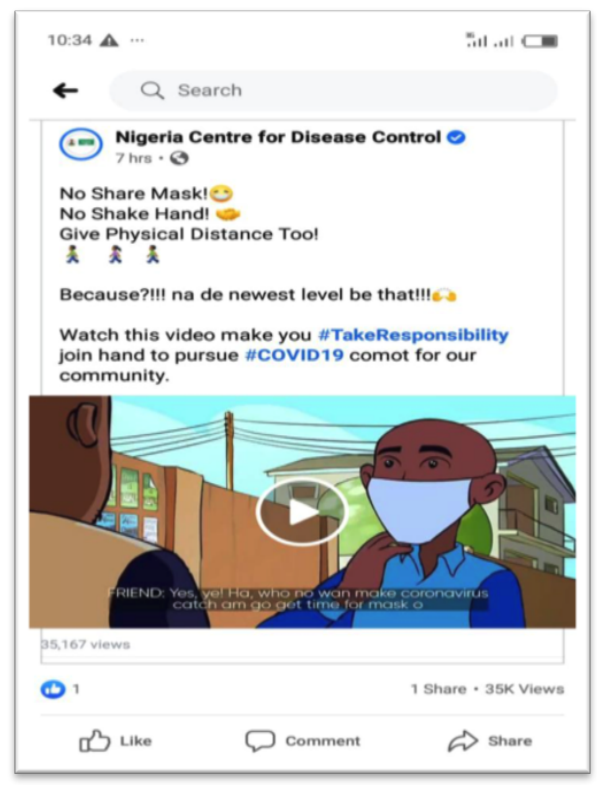

Figure 4. Audio-visual and local pidgin strategy of preventive measures.

With simple, straightforward, colorful illustrations, social media can enlighten people to take responsibility and prevent the spread of the disease (Figure 2). While Figures 3 and 4 demonstrate the science behind masking. Figure 4 has interestingly used audio-visual strategies and Nigeria pidgin to explain the importance of masks. 
Accurate information plays an essential role in addressing health and other social problems everywhere. Barua et al. (2020) affirm that the proliferation of misinformation on social media platforms is faster than the spread of COVID-19 and require authorities to initiate proper safety measures concerning dangerous misinformation. The COVID-19 pandemic, as Tasnim et al. (2020: 171) agree, has "fueled the surge of numerous rumors, hoaxes, and misinformation regarding the etiology, outcomes, prevention, and cure of the disease." They suggest adopting advanced technologies such as natural language processing to delete online content that lacks a scientific basis. Besides, people who are motivated by self-promotion and entertainment and those with deficits in self-regulation are more prone to share unsubstantiated information (Islam et al., 2020).

\section{b. Focus on the solutions, not the problems}

The digital age can easily lead to information overload. The pandemic information should not stress the scary figures, numbers, and statistics; but emphasize the concrete steps that may ameliorate the health condition (Figure 5).

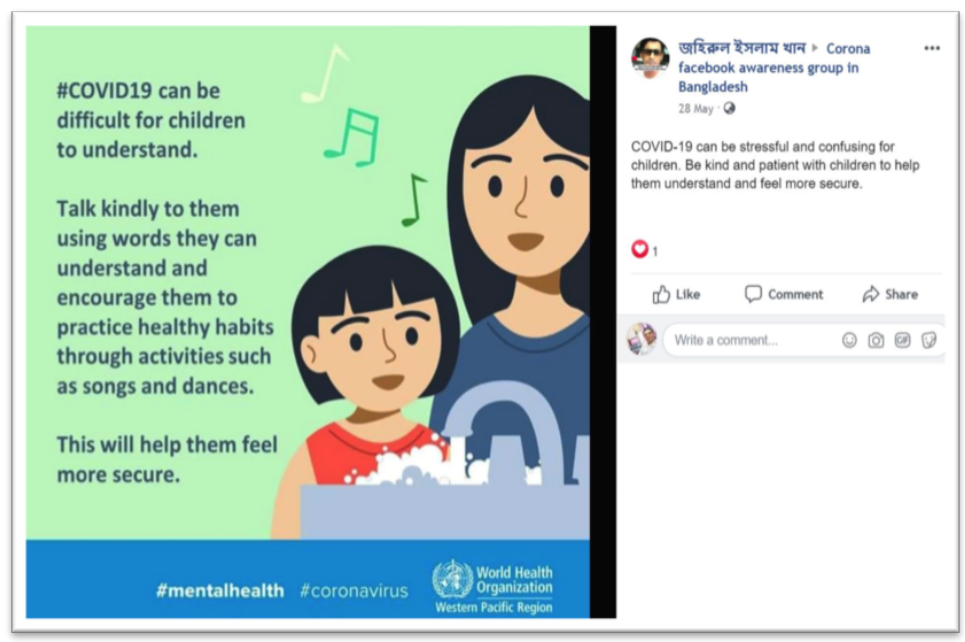

Figure 5. Focusing on solution.

Figure 5 is similar to the one by WHO, offering information on how to emotionally handle children who may not understand the restriction imposed by COVID-19. The use of cartoon images of children appeals to the visual sense and helps adults secure children's psychological health amidst the COVID-19 pandemic in Bangladesh (Yeasmin et al., 2020). 


\section{c. Counter of fake information}

We live in a cybernetic world where fake news, false information, and half-truths are peddled in the digital sphere at an alarming rate. It is crucially essential to dispel rumors and all unwholesome information about the cause, origins, characteristics, preventions, and treatments of disease outbreaks in times of disease outbreaks. We should offer actual, credible, accurate, and factual information as a counter. Figure 6 uses cartoon characterization and the Nigeria pidgin to confront the false notion that only older people with comorbidities are vulnerable to contract COVID-19.

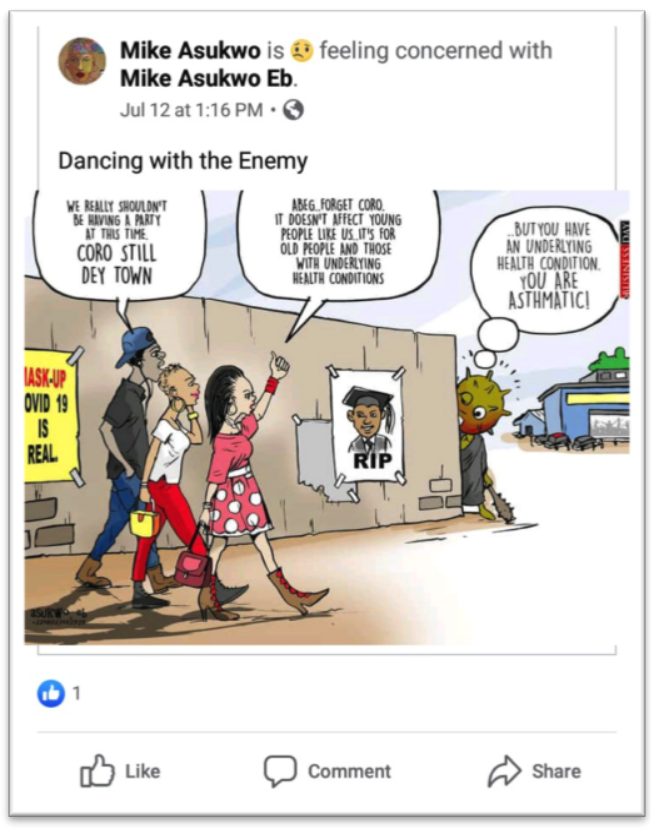

Figure 6. Countering of fake news.

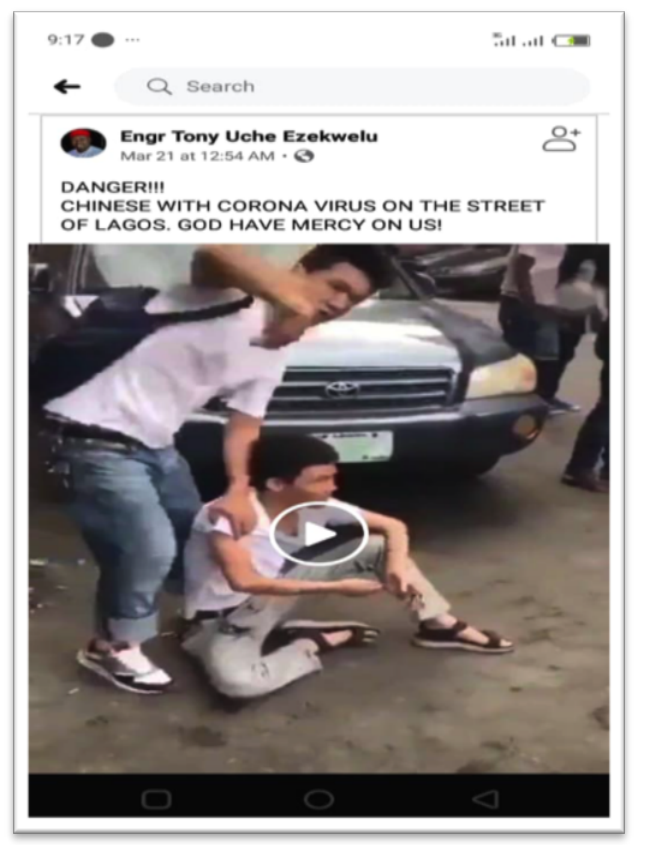

Figure 7. An example of racism.

\section{d. Stand against racism, finger-pointing, and stigmatization}

We may notice that social media platforms have promoted racism (the coronavirus is a China virus), finger-pointing (the disease started in the wild-animal market in Wuhan), stigmatization (avoid relating with those infected even after they have recovered), scapegoats (this or that country will pay for it after the outbreak). Figure 7 demonstrates the unhelpful tendency for social network users to resort to fingerpointing and racism by insinuating that China is to blame for the COVID-19 pandemic. However, social media networks can also be effective in kicking against these by seeing the outbreaks as the local, national, or global threat to health, society, and economy that must be fought concertedly, stridently, and globally. 


\section{e. Use scientific (evidence-based) facts to allay fears}

Fear may become more dangerous than the pandemic itself. However, cyberspace provides an abundance of accurate, factual, research-based information available to all users of social network platforms if they care to search. The users must conduct such searches and disseminate the information to reduce fears and empower users to confidently confront disease outbreaks as individuals, communities, institutions, nations, and regions. It is crucial to rely on trusted scientific publications or periodicals to bring up facts to allay the fears. In contrast, hear-says, urban-legend, the idle talk should all be avoided as they may escalate the concern. Figure 8, a Bangladesh example, illustrates that the best protection from masking comes when interacting people all use face masks and observe physical distancing.

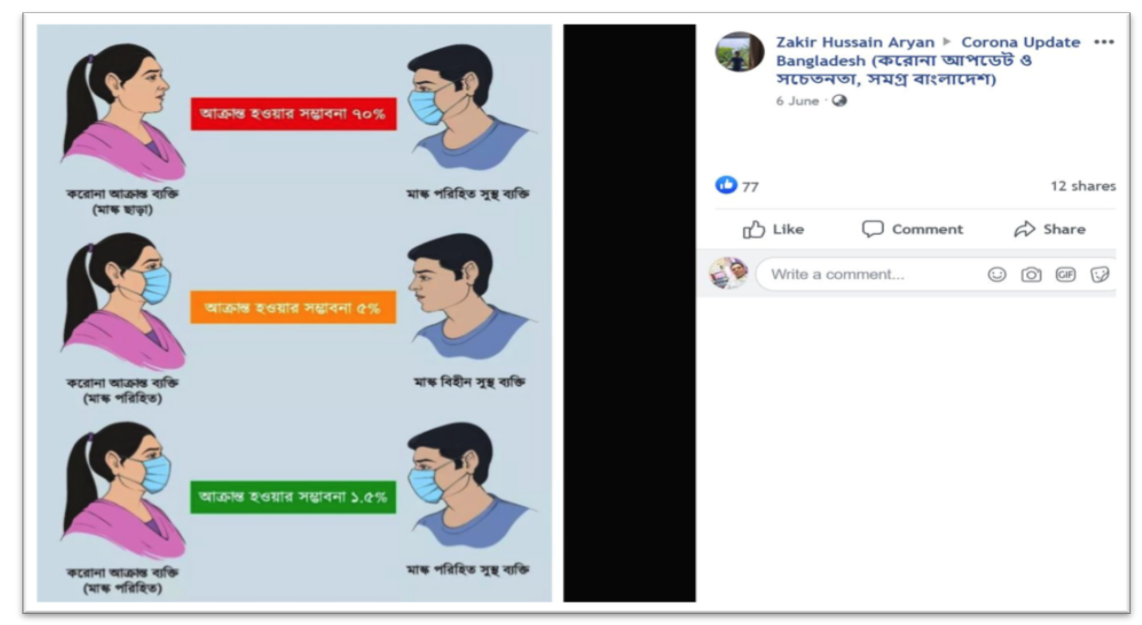

Figure 8. Use of science-based facts about using the mask.

In this sense, the media of communication may help to democratize science, empowering the public to understand the situations and make the decision. The media assists science and technology to make an impact on contemporary society, the human future, and the environment (Jucan \& Jucan, 2014). Communication can promote scientific values, frame science into the public consciousness, and increase public participation and public policy (Jamieson, 2015; Kappel \& Holmen, 2019).

\section{f. Explain numbers, figures, and statistics meaningfully}

During disease outbreaks, the public is usually inundated with copious amounts of epidemiological statistics. Quite often, the average citizen hardly makes sense of them if they do not become more confounded. Statistics in social media should be simplified, transformed into discernible informational graphics explaining the extent 
of the outbreak, allowing people to appropriately grasp the problem and get the simple-to-do actions they can undertake to protect themselves (Figure 9).

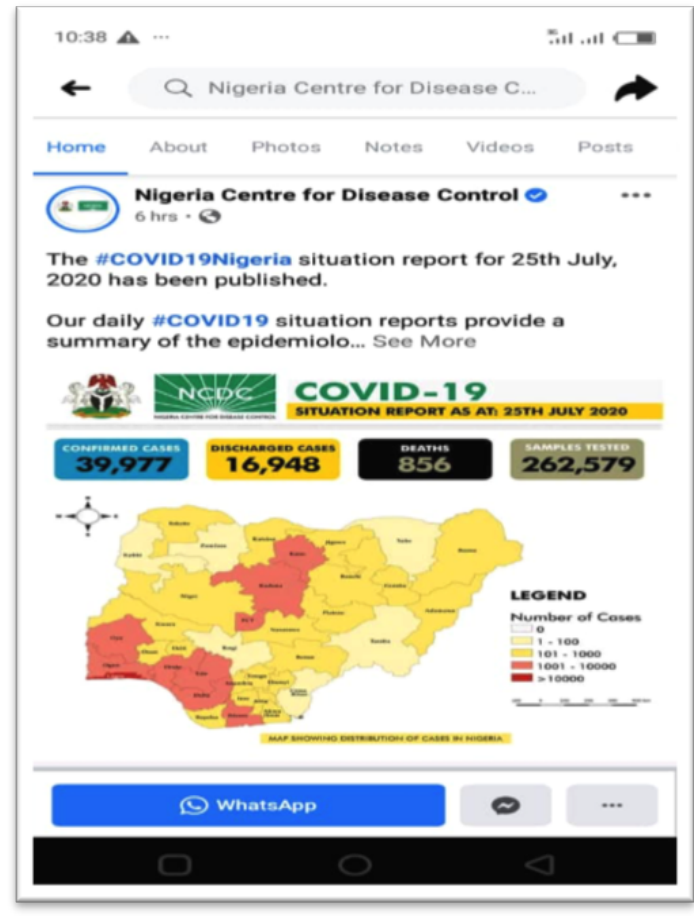

Figure 9. Statistic-based illustration.

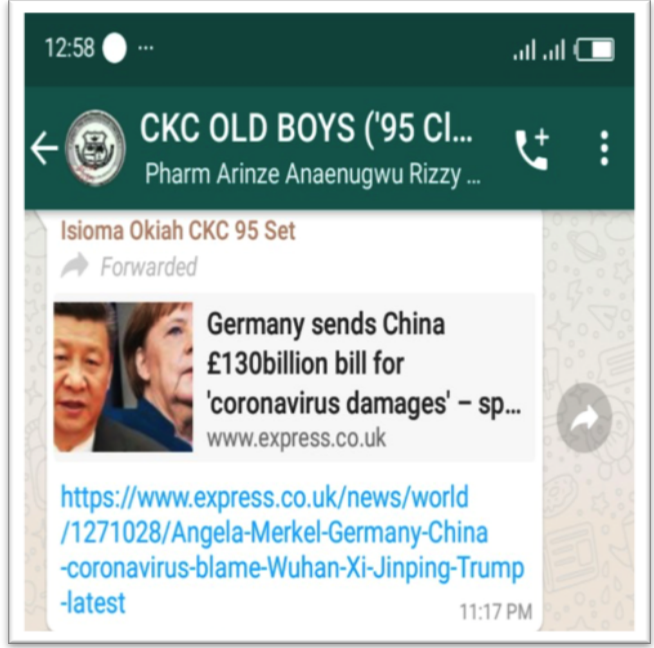

Figure 10. An example of finger pointing.

\section{g. Confront conspiracy theories}

Conspiracy theories are dangerous as they can distract attention from diseasetackling initiatives. In the social media, we find conspiracies such as, "Covid-19 is caused by high radiations of the $5 \mathrm{G}$ cellular phone networks," or that coronavirus was a biological weapon designed in a Chinese lab that got spilled accidentally (Figure 10). Social media users should recognize them as baseless and ready to search for the correct information to control them.

\section{h. Watch out for pseudoscience, denials, and contrariness}

Pandemics are bioscience issues, and therefore as in other sciences, they are steeped in controversies and often contentious among scientists. Fringe scientists and others deny stark realities, and others are contrary views. The social media enthusiast should watch out for these groups, identify them, not take sides, but counter their opinions with the generally held consensus of the more significant majority of mainstream science (bioscience) ideas. 


\section{i. Avoid the temptation to trivialize and sensationalize the pandemic}

The current pandemic is too severe to be the source of a joke or a hype. Rather than use social media for such purposes, scientific efforts should galvanize people to correct the tendency to exaggerate or treat disease outbreaks as entertainment. Users of social media platforms should frequently source credible links and sources of evidence-based and scientific information, including the information on untested, alternative therapies and treatment claims. The same data should be shared with others in the networks. Users should take ethical considerations to ensure that texts, videos, photos, and audios on social media platforms are not offensive.

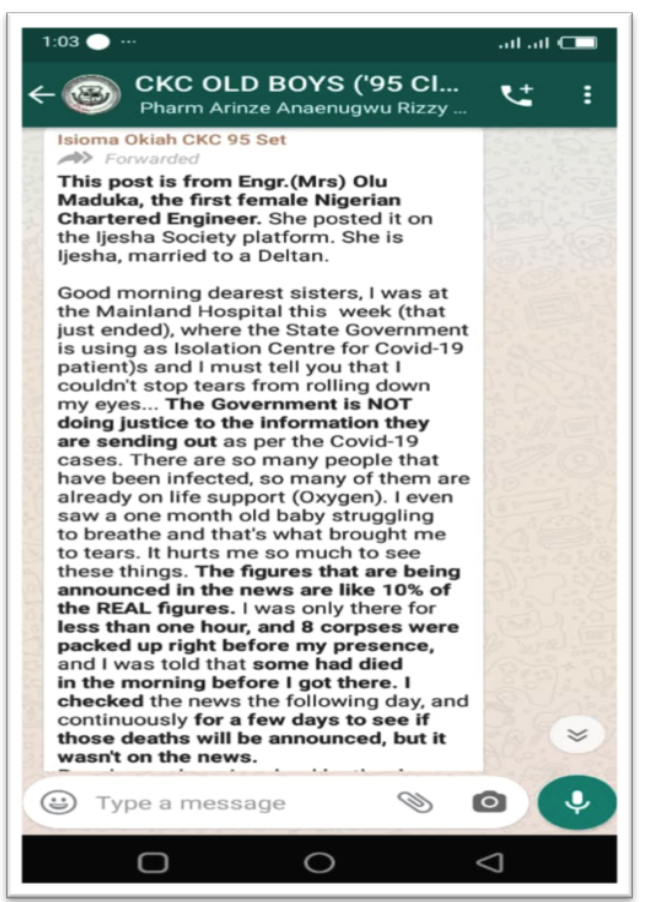

Figure 11. An example of sensationalism.

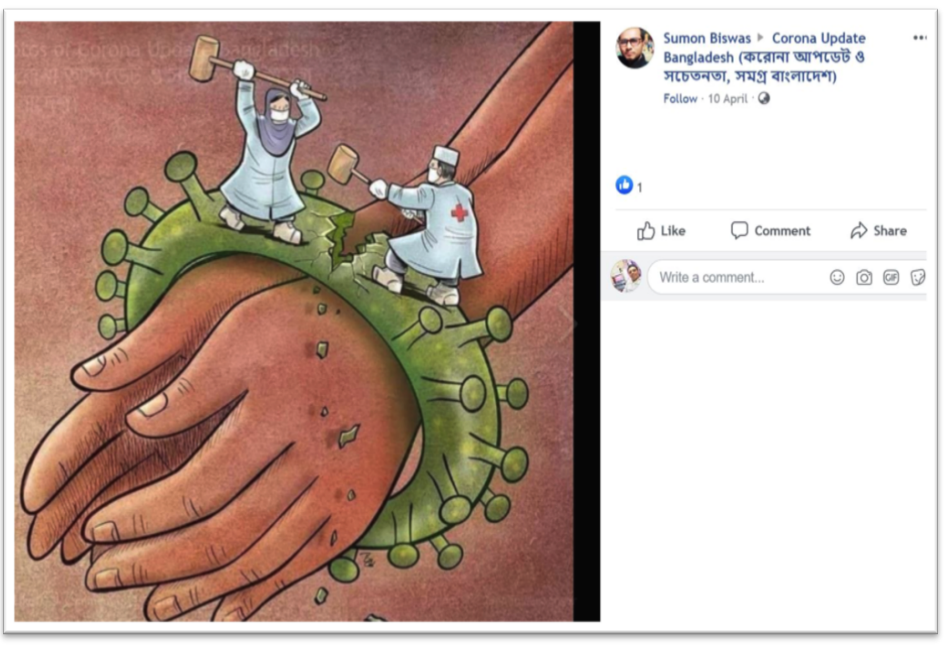

Figure 12. In praise of health personnel. 
Figure 11 is user-generated textual content circulating in the social network circle and bears false information on COVID-19 in Nigeria. It tends towards sensationalizing the pandemic by blowing it out of proportion. While Figure 12, captured from a social media user in Bangladesh, uses the graphic image to reassure people and underscore the heroic efforts of health personnel and the government in fighting the pandemic. It is a single illustration that speaks volumes.

\section{j. Recourse to local language}

We live in the English language-dominated world. However, this cuts out nonEnglish readers, especially in the digital space. Fortunately, there is language translation software that can translate many languages. Social media users should avail themselves of this facility to share information about the pandemic. This facility would further democratize health/medical information and accommodate a vast majority of non-English users and co-opt them into local, national, and global efforts to fight disease outbreaks (Figure 13 \& 14).

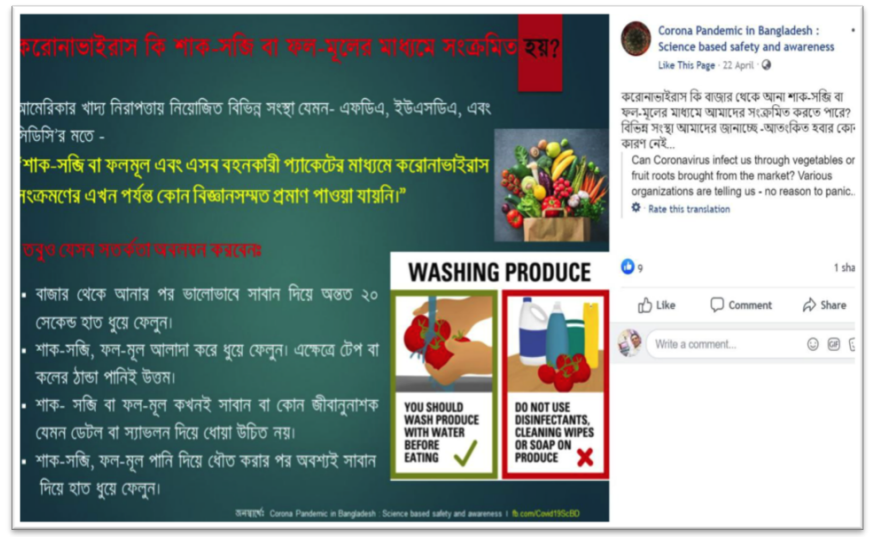

Figure 13. The use of local language, advising to wash vegetables and fruits with fresh water.

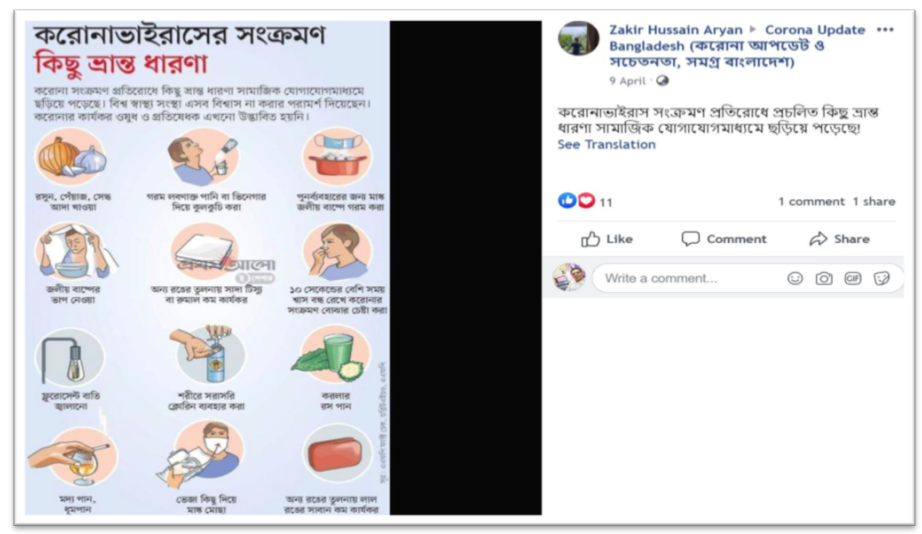

Figure 14. The use of local language, confronting misinformation about the spread of Covid-19. 


\section{Conclusion}

This paper has shown that social media, especially Facebook, have become a veritable avenue for communicating information on the COVID-19 pandemic, whether the message is usergenerated or shared from other sources. However, this platform has been used both for positive and negative purposes. From examining the COVID-19 related text in Facebook, we may conclude that users may use social media to support preventive measures against COVID-19well to get help and treatment through texts, pictures, graphics, statistics, and local languages.

As the illustrations from the two countries have demonstrated, Facebook has been deployed to support preventive measures, focus on the solutions, counter fake information, stand against racism and stigmatization, emphasize scientific facts to allay fears, confront conspiracy theories, deal with pseudoscience and denials, explain numbers and statistics meaningfully, avoid the temptation to trivialize and sensationalize, and translate the content into local languages. Unfortunately, other users have used it to stoke conspiracy theories, spread rumors, falsehood, and sensational news, etc. This problem underscores the need for social network users to acquire keen skills in digital literacy, especially the ability to verify digital information from credible sources.

However, the effectiveness of these communication strategies on behavioral changes is not the focus of this article. We, therefore, suggest further studies on the influence of social media communication on COVID-19 on compliance with COVID protocols. The paper has also offered the option to reconceptualize the notion of strategic communication in the context of social media uses to address the COVID-19 health crisis.

\section{Notes on contributors}

Habib Mohammad Ali is an assistant professor at the Department of Media Studies \& Journalism, University of Liberal Arts Bangladesh. Address: Dhanmondi 4/A, Dhaka, Bangladesh. Email: habib.mohammad@ulab.edu.bd.

Herbert Batta is an associate professor at the Department of Communication Arts, University of Uyo, Nigeria. Email: drherbbatta@gmail.com.

Henry C. Ogaraku is a lecturer at the Department of Mass Communication, Lagos Aviation \& Maritime Business Academy, Uyo Campus, Nigeria. Email: ogaraku.henry@yahoo.com. 


\section{References}

Anwar, S., Nasrullah, M., \& Hosen, M. J. (2020). COVID-19 and Bangladesh: Challenges and how to address them. Frontiers in Public Health, 8. https://doi.org/10.3389/fpubh.2020.00154

Barnes, J. A. (1954). Class and committees in a Norwegian island parish. Human Relations, 7(1), 3958. https://doi.org/10.1177/001872675400700102

Barua, Z., Barua, S., Aktar, S., Kabir, N., \& Li, M. (2020). Effects of misinformation on COVID-19 individual responses and recommendations for resilience of disastrous consequences of $\begin{array}{llllll}\text { misinformation. Progress in Disaster } & \text { Science, } & 8, & 100119 .\end{array}$ https://doi.org/10.1016/j.pdisas.2020.100119

Bunker, D. (2020). Who do you trust? The digital destruction of shared situational awareness and the COVID-19 infodemic. International Journal of Information Management, 55, 102201. https://doi.org/10.1016/j.ijinfomgt.2020.102201

Cassel, J. (1976). The contribution of the social environment to host resistance 1. American Journal of Epidemiology, 104(2), 107-123. https://doi.org/10.1093/oxfordjournals.aje.a112281

Chan, A. K. M., Nickson, C. P., Rudolph, J. W., Lee, A., \& Joynt, G. M. (2020). Social media for rapid knowledge dissemination: Early experience from the COVID-19 pandemic. Anaesthesia, 75(12), 1579-1582. https://doi.org/10.1111/anae.15057

Chetty, L. R. (2012). The role of science and technology in the developing world in the 21st century. https://ieet.org/index.php/IEET2/more/chetty20121003

Dadaczynski, K., Okan, O., Messer, M., Leung, A. Y. M., Rosário, R., Darlington, E., \& Rathmann, K. (2021). Digital health literacy and web-based information-seeking behaviors of University Students in Germany during the COVID-19 pandemic: Cross-sectional survey study. Journal of Medical Internet Research, 23(1), e24097. https://doi.org/10.2196/24097

Davies, R., \& Priestley, C. (2017). Science literacy in developing countries: Landscape survey. http://www.nida-net.org/documents/8/SL_Researcht_Report_Final.pdf.

Daymon, C., \& Immy, H. (2011). Qualitative research methods in public relations and marketing communications (2nd ed.). Routledge.

Fergie, G., Hunt, K., \& Hilton, S. (2016). Social media as a space for support: Young adults' perspectives on producing and consuming user-generated content about diabetes and mental health. Social Science \& Medicine, 170, 46-54. https://doi.org/10.1016/j.socscimed.2016.10.006

Finset, A., Bosworth, H., Butow, P., Gulbrandsen, P., Hulsman, R. L., Pieterse, A. H., Street, R., Tschoetschel, R., \& van Weert, J. (2020). Effective health communication - a key factor in fighting the COVID-19 pandemic. Patient Education and Counseling, 103(5), 873-876. https://doi.org/10.1016/j.pec.2020.03.027

Hauer, M. K., \& Sood, S. (2020). Using social media to communicate sustainable preventive measures and curtail misinformation. Frontiers in Psychology, $11,2779$. https://doi.org/10.3389/fpsyg.2020.568324

Holmes, R. (2020). “Is COVID-19 social media's levelling up moment?" Forbes. https://www.forbes.com/sites/ryanholmes/2020/04/24/is-covid-19-social-medias-levellingup-moment/\#32e022256c6o

Huber, B., Barnidge, M., Gil de Zúñiga, H., \& Liu, J. (2019). Fostering public trust in science: The role of social media. Public Understanding of Science, 28(7), 759-777. https://doi.org/10.1177/0963662519869097

Islam, A. K. M. N., Laato, S., Talukder, S., \& Sutinen, E. (2020). Misinformation sharing and social media fatigue during COVID-19: An affordance and cognitive load perspective. Technological Forecasting and Social Change, 159, 120201. https://doi.org/10.1016/j.techfore.2020.120201 
Islam, M. S., Ferdous, M. Z., \& Potenza, M. N. (2020). Panic and generalized anxiety during the COVID-19 pandemic among Bangladeshi people: An online pilot survey early in the outbreak. Journal of Affective Disorders, 276, 30-37. https://doi.org/10.1016/j.jad.2020.06.049

Jamieson, K. H. (2015). Communicating the values and values of science. Issues in Science and Technology, 32(1), 34-35. https://issues.org/communicating-the-value-and-values-of-science/

Jucan, M. S., \& Jucan, C. N. (2014). The power of science communication. Procedia - Social and Behavioral Sciences, 149, 461-466. https://doi.org/10.1016/j.sbspro.2014.08.288

Kappel, K., \& Holmen, S. J. (2019). Why science communication, and does it work? A taxonomy of science communication aims and a survey of the empirical evidence. Frontiers in Communication, 4. https://doi.org/10.3389/fcomm.2019.00055

Kumar, S., Xu, C., Ghildayal, N., Chandra, C., \& Yang, M. (2021). Social media effectiveness as a humanitarian response to mitigate influenza epidemic and COVID-19 pandemic. Annals of Operations Research. https://doi.org/10.1007/s10479-021-03955-y

Leopoldina, Acatech, \& Akademienunion. (2017). Social media and digital science communication: Analysis and recommendations for dealing with chances and risks in a democracy.

Liang, X., Su, L. Y.-F., Yeo, S. K., Scheufele, D. A., Brossard, D., Xenos, M., Nealey, P., \& Corley, E. A. (2014). Building buzz. Journalism \& Mass Communication Quarterly, 91(4), 772-791. https://doi.org/10.1177/1077699014550092

Liao, Q., Yuan, J., Dong, M., Yang, L., Fielding, R., \& Lam, W. W. T. (2020). Public engagement and government responsiveness in the communications about COVID-19 during the early epidemic stage in China: Infodemiology study on social media data. Journal of Medical Internet Research, 22(5), e18796. https://doi.org/10.2196/18796

McClain, C. R. (2017). Practices and promises of Facebook for science outreach: Becoming a "Nerd of Trust.” PLOS Biology, 15(6), e2002020. https://doi.org/10.1371/journal.pbio.2002020

Moreno, A., Fuentes-Lara, C., \& Navarro, C. (2020). Covid-19 communication management in Spain: Exploring the effect of information-seeking behavior and message reception in public's evaluation. El Profesional de La Información, 29(4). https://doi.org/10.3145/epi.2020.jul.o2

Osterrieder, A. (2013). The value and use of social media as communication tool in the plant sciences. Plant Methods, 9(1), 26. https://doi.org/10.1186/1746-4811-9-26

Sandalova, E., Ledford, J. G., Baskaran, M., \& Dijkstra, S. (2019). Translational medicine in the era of social media: A survey of scientific and clinical communities. Frontiers in Medicine, 6, 152. https://doi.org/10.3389/fmed.2019.00152

Tasnim, S., Hossain, M. M., \& Mazumder, H. (2020). Impact of rumors and misinformation on COVID-19 in social media. Journal of Preventive Medicine and Public Health, 53(3), 171-174. https://doi.org/10.3961/jpmph.20.094

Udodiong, I. (2020). Here is how Nigerians are using the internet in 2019. Pulse.Ng. https://www.pulse.ng/bi/tech/how-nigerians-are-using-the-internet-in-2019/kz097rg

Van Eperen, L., \& Marincola, F. M. (2011). How scientists use social media to communicate their research. Journal of Translational Medicine, 9(199), 1-3. https://doi.org/10.1186/1479-5876-9199

Wilkinson, C., \& Weitkamp, E. (2013). A case study in Serendipity: Environmental researchers use of traditional and social media for dissemination. PLoS ONE, 8(12), e84339. https://doi.org/10.1371/journal.pone.0o84339

Yeasmin, S., Banik, R., Hossain, S., Hossain, M. N., Mahumud, R., Salma, N., \& Hossain, M. M. (2020). Impact of COVID-19 pandemic on the mental health of children in Bangladesh: A crosssectional study. Children and Youth Services Review, 117, 105277. https://doi.org/10.1016/j.childyouth.2020.105277 
Habib Mohammad Ali, Herbert Batta, and Henry C. Ogaraku. Communicating COVID-19 Pandemic on Facebook: Illustrations from Users' Screenshots from Nigeria and Bangladesh

Zielińska, I. (2017). The influence of social media on science communication: Strategies of GMO opponents on Facebook. Adeptus, 1O, 1153. https://doi.org/10.11649/a.1513 